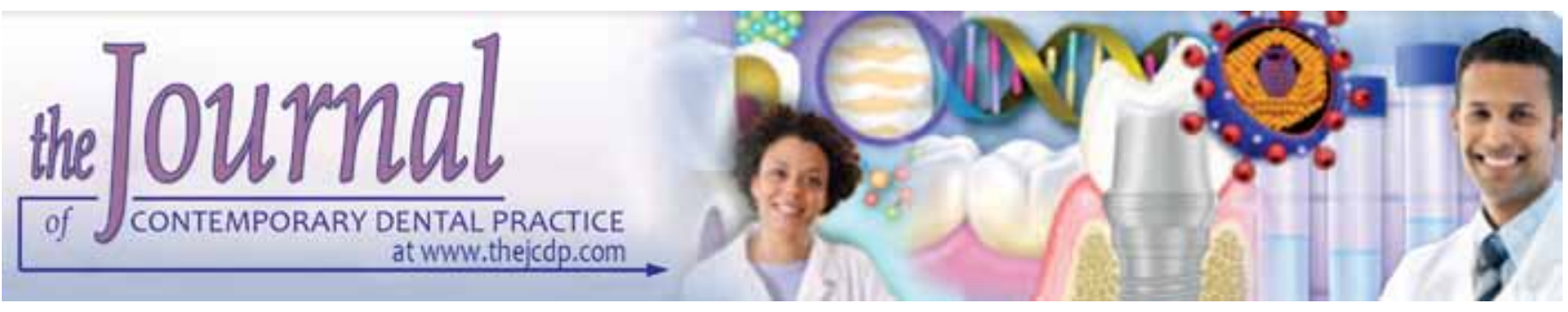

\title{
Long-Term Surface Hardness and Monomer Conversion of a Nanofilled and a Microhybrid Composite Resin
}

Fernanda Ferreira Jassé, Carlos Henrique Braga Borges, Mateus Rodrigues Tonetto, Alessandra Nara de Souza Rastelli Vanderlei Salvador Bagnato, Edson Alves de Campos, Reidson Stanley Soares dos Santos, Matheus Coelho Bandeca José Roberto Cury Saad

\section{ABSTRACT}

Objective: This study aims to evaluate the degree of conversion (DC) and hydrolytic degradation through the Vickers hardness test (HV) of a nanofilled (Filtek $\left.{ }^{\mathrm{TM}} \mathrm{Z}-250,3 \mathrm{M}\right)$ and a microhybrid (Filtek ${ }^{\mathrm{TM}}$ Supreme-XT, 3M) composite resin.

Materials and methods: Eight disk-shaped specimens $(4 \mathrm{~mm}$ diameter $\times 2 \mathrm{~mm}$ thick, ISO 4049) of each material were prepared for each test. Composites were inserted into single increment in a metallic matrix and light-cured for 40 seconds. $\mathrm{VH}$ readings were performed for each specimen at predetermined intervals: immediately after polymerization (control), 1, 2, 3, 7, 14, 21, 30 and 180 days. After curing, initial hardness measurements were performed and the specimens were immersed in artificial saliva at $37^{\circ} \mathrm{C}$. For $\mathrm{DC}(\%)$, specimens were ground, pressed with $\mathrm{KBr}$ and analyzed by FT-IR spectrophotometer.

Results: Student t-test showed that there was no difference between the resins for DC $(p=0.252)$. ANOVA analysis revealed that Z-250 VH means were all greater than S-XT, for both top and bottom surfaces, whatever the storage-period in artificial saliva $(p<0.001)$. After 180 days of storage, the hardness obtained for S-XT was similar with that at the baseline, for both top and bottom surfaces. While for Z-250 hardness was not significantly different from baseline only for top surface, but there was a significant decrease observed in hardness for bottom surface.

Conclusion: The materials tested showed no evidence of hydrolytic degradation in a significant way, in a 6-month storagetime in artificial saliva. Nanofilled resin presents a monomer conversion comparable to the conventional microhybrid.

Keywords: Composite resins, Hardness tests, Artificial saliva, Fourier transform infrared spectroscopy.

How to cite this article: Jassé FF, Borges $\mathrm{CHB}$, Tonetto MR, de Souza Rastelli AN, Bagnato VS, de Campos EA, Bandeca MC, Saad JRC. Long-Term Surface Hardness and Monomer Conversion of a Nanofilled and a Microhybrid Composite Resin. J Contemp Dent Pract 2013;14(5):876-882.

Source of support: Nil

Conflict of interest: None declared

\section{INTRODUCTION}

The visible light-curable materials have become almost universal as dental restorative materials in modern dental practice. ${ }^{1}$ These materials' popularity is mainly because they allow a comfortable working time directly controlled by the professional, present color options leading to excellent esthetic results and have adequate mechanical properties. ${ }^{2,3}$

Nowadays, a variety of such materials are commercially available for the choice of the clinicians when they are confronted with the need to restore the tooth structure. Among restorative materials, the composite resins are the ones that have stood out, because their constant improvement has been expanding their indications. The composite resins were classified according to the size of their filler particles as: hybrid, microhybrid and microfilled. ${ }^{4}$ Since the advent of nanotechnology, the nanofilled composites also became available for clinical use. A typical nanofilled composite has a filler particle system that combines nanometer silica particles and zirconia-silica nanoclusters. ${ }^{4}$ Its filler constituents represent $59.5 \%$ in volume, such as several hybrid and microhybrid composites. ${ }^{4}$

In general, dental composites are essentially constituted by mineral fillers dispersed in an organic resin matrix and a photoinitiator system. ${ }^{5}$ The resin matrix consists of a long-chain multifunctional monomer. When polymerized, that monomers result in a three-dimensional cross-linked network called polymer. The monomer bisphenol A glycidyl methacrylate (Bis-GMA) is the most commonly used in the formulation of dental composites and is characterized by a rigid and long molecule with reactive carbon-double-bonds at both ends. ${ }^{6,7}$ The extent of the reaction in which the monomer is converted to polymer is identified by the degree of conversion that corresponds to the percentage of monomer carbon-double-bonds that are converted into carbon-singlebonds as a result of the polymerization process. ${ }^{7}$ 
Since the introduction of photoactivated resin composite, quality of polymerization and its consequences have become a major concern for researchers, whereas the adequate polymerization of resin materials is a key factor to obtain good physical properties and clinical performance of the restorations. ${ }^{1}$ Several studies have shown that many of the physical and chemical properties of composites such as hardness, wear resistance, compressive strength, flexural strength, dimensional stability, solubility, discoloration and degradation reactions depend on the degree of polymerization of their organic components. ${ }^{8,9}$ Thus, the degree of conversion is a codetermining factor of the restorative resins ' properties. ${ }^{10}$ Other studies also found that the release of unreacted monomer that remains in the material ${ }^{1,11}$ can stimulate bacteria growth around the restoration ${ }^{12}$ and cause allergic reactions in some patients. ${ }^{13}$

Photoactivated dental composites usually achieve a degree of conversion ranging from 43 to $75 \%$, mostly depending on the composition of the composite, radiation intensity and exposure time. ${ }^{3,14}$ More specifically, factors that affect degree of conversion are: resin matrix, diluent concentration, concentration of photoinitiator and amine, shade and translucency of the material, shape and quantity of inorganic particles, refractive indices of the matrix and inorganic particles. While factors related to photoactivation are the wavelength and intensity of the light source, the irradiation time and the distance between the light source and the surface of the resin. ${ }^{1,10,15,16}$

The degradation reactions of resin materials are also relevant. Resin-based materials are required to have longterm durability in the oral cavity, which is a complex environment that subjects the material to challenges like the contact with saliva and its variety of inorganic and organic groups and microorganisms. ${ }^{17,18}$ However, the clinical performance of these materials over time is frequently correlated with degradation characteristics, since these can directly affect their mechanical properties. ${ }^{19}$ The deterioration over time has been attributed to chemical reactions that are naturally accelerated by heat. ${ }^{20}$ In the oral environment, reports of degradation of composite resin restorations, which are located in areas not exposed to abrasive and compressive forces suggests the occurrence of chemical degradation. The water is directly related to the resin-based materials organic matrix deterioration, since the sorption of the liquid results in a process of diffusion in the matrix, causing its degradation and resulting in decreased mechanical properties. ${ }^{21}$ Among these properties, the hardness of the polymers can be compromised by the hydrolytic degradation of methacrylate monomers at high temperatures. ${ }^{20}$ Thus, substances such as saliva, food and beverages can result in deleterious effects to the restorations with resin-based materials, ${ }^{17}$ since they are intermittent or continuous sources of chemical degradation. ${ }^{21}$ Söderholm et al. ${ }^{22}$ discussed the composite resins hydrolytic degradation process and related the phenomenon to the presence of fissures and cracks in the matrix and the displacement of filler particles. Another study have detected that excess water acts as a plasticizer in resin materials. ${ }^{18,23}$

Surface hardness and degree of monomer conversion are important properties of restorative filling materials. Seeking to better understand the behavior of materials widely used in clinical dentistry the aim of this study was to evaluate the influence of the composition of two resin composites on their degrees of conversion, and also on its Vickers hardness after 6-month-storage in artificial saliva as a means of predicting their behavior toward the hydrolytic degradation.

\section{MATERIALS AND METHODS}

\section{Materials Tested}

Two different visible light-cured resin composites were investigated: a microhybrid (Filtek ${ }^{\mathrm{TM}} \mathrm{Z}-250$, 3M Dental Products, St Paul, MN, USA) and a nanofilled (Filtek ${ }^{\mathrm{TM}}$ Supreme XT, 3M Dental Products, St Paul, MN, USA). Table 1 summarizes the characteristics of restorative materials used in the study.

\section{Specimen Preparation}

For Vickers hardness test eight disk-shaped specimens $(n=8)$ for each material were fabricated using a metallic mold having an internal diameter of $4 \mathrm{~mm}$ and thickness of $2 \mathrm{~mm}$ that was placed on a flat glass plate on top of a mylar strip. The mold was filled with the composite in a single

\begin{tabular}{|c|c|c|c|c|c|c|c|}
\hline Material & Manufacturer & Shade & Type & $\begin{array}{l}\text { Organic } \\
\text { matrix }\end{array}$ & Filler content & $\begin{array}{l}\text { Filler } \\
\text { volume }\end{array}$ & $\begin{array}{l}\text { Batch } \\
\text { number }\end{array}$ \\
\hline $\begin{array}{l}\text { Filtek }^{T M} \\
\text { Supreme XT } \\
\text { (S-XT) }\end{array}$ & $\begin{array}{l}\text { 3M ESPE (St. } \\
\text { Paul, MN, } \\
\text { USA). }\end{array}$ & $\mathrm{A} 2 \mathrm{E}$ & $\begin{array}{l}\text { Nanofilled } \\
\text { universal resin } \\
\text { composite }\end{array}$ & $\begin{array}{l}\text { Bis-GMA, } \\
\text { Bis-EMA, } \\
\text { UDMA, } \\
\text { TEGDMA }\end{array}$ & $\begin{array}{l}\text { Combination of agglomerated } \\
\text { particles of zirconia/silica with mean } \\
\text { size } 0.6 \text { to } 1.4 \text { microns; primary } \\
\text { particle size of } 5-20 \mathrm{~nm} \text {; non- } \\
\text { aggregated silica particles of } 20 \mathrm{~nm} \text {. }\end{array}$ & $59.5 \%$ & $6 B W$ \\
\hline $\begin{array}{l}\text { Filtek }^{T M} \\
\text { Z-250 } \\
(\mathrm{Z}-250)\end{array}$ & $\begin{array}{l}\text { 3M ESPE (St. } \\
\text { Paul, MN, } \\
\text { USA). }\end{array}$ & $\mathrm{A} 2$ & $\begin{array}{l}\text { Microhybrid } \\
\text { universal resin } \\
\text { composite }\end{array}$ & $\begin{array}{l}\text { Bis-GMA, } \\
\text { Bis-EMA, } \\
\text { UDMA, } \\
\text { TEGDMA }\end{array}$ & $\begin{array}{l}\text { Particles of zirconia/silica with sizes } \\
\text { varying between } 0.01 \text { and } 3.5 \mu \mathrm{m} \\
\text { (average size: } 0.6 \mu \mathrm{m} \text { ) }\end{array}$ & $60 \%$ & $8 \mathrm{FF}$ \\
\hline
\end{tabular}


increment and the surface was covered with a mylar strip and made flat by pressuring it with a glass sheet ( $1 \mathrm{~mm}$ thick) and a weight of $1 \mathrm{Kg}$ to pack the composite resin and extrude excess material. Materials were then photoactivated for 40 second of irradiation time through the glass sheet using a LED Light Curing Unit (Celalux ${ }^{\circledR}$, Voco, Germany). The set disks were separated from the mold and the upper surface of each disk was identified as a guide for top and bottom surfaces hardness measurements.

For degree of conversion measurements, more eight specimens $(n=8)$ were made for each resin composite identically to the ones obtained for $\mathrm{VH}$ measurements.

\section{Storage Periods and Hardness Measurements}

Using a millimeter ruler and a scalpel blade two lines were drawn on the top and bottom surfaces, dividing the specimens into quadrants. Immediately after light polymerization the surface hardness of the specimens were determined using a digital microhardness tester MMT-3 (Buehler, Lake Bluff, Illinois, USA) with a diamond Vickers indentor, to assess the initial condition of the specimens. The specimens were placed on the instrument platform with the surface under test facing the indenter. A load of $50 \mathrm{gf}$ was applied to the surface with a dwell time of 30 second and eight indentations (two in each quadrant) were performed on the top (exposed to light source) and bottom (opposite to light source) surfaces of each specimen. The Vickers hardness (VH) numbers of each specimen was then recorded.

After the initial analysis (baseline), the specimens were stored in artificial saliva at $37^{\circ} \mathrm{C}$. Hardness tests were performed after 1, 2, 3, 7, 14, 21, 30 and 180 days, in immersion. Before each evaluation, the specimens were washed for 1 minute in tap water and then blotted dry. The artificial saliva was changed weekly.

\section{Degree of Conversion (\%)}

After 24 hours of curing, the composites were pulverized into a fine powder. The composite powder $(5 \mathrm{mg}$ ) was thoroughly mixed with bromide potassium $(\mathrm{KBr})$ powder salt $(100 \mathrm{mg})$. The obtained mixture was inserted into a pelleting device and then pressed through the use of a press with a load of 10 time during 1 minute to obtain a pellet.

The pellet was placed into a holder attachment into the spectrophotometer (Nexus-470 FT-IR, Thermo Nicolet, EUA) to measure the degree of conversion of the composite resin that is provided by the number of double-carbon bonds, which are converted into single-carbon bonds. Fourier transform infrared spectroscopy (FT-IR) spectra of both uncured and cured samples were obtained using an accessory of diffuse reflectance. The spectra were recorded in the absorbance operating mode under the predetermined settings: 32 scans, $4 \mathrm{~cm}^{-1}$ resolution and 300 to $4000 \mathrm{~cm}^{-1}$ wavelength.

In order to determine the percentage of unreacted doublecarbon bonds $(\% \mathrm{C}=\mathrm{C})$, it was obtained the ratio between the absorbance intensities of aliphatic $\mathrm{C}=\mathrm{C}$ (peak at 1638 $\mathrm{cm}^{-1}$ ) and the internal standard before and after the curing of the composite, represented by the aromatic C-C (peak at $1608 \mathrm{~cm}^{-1}$ ). The degree of conversion was determined according to the following formula:

$$
\text { DC }(\%)=1-\frac{\left(1638 \mathrm{~cm}^{-1} / 1608 \mathrm{~cm}^{-1}\right) \text { cured }}{\left(1638 \mathrm{~cm}^{-1} / 1608 \mathrm{~cm}^{-1}\right) \text { uncured }} \times 100
$$

\section{Statistical Analysis}

VH data were analyzed using ANOVA of repeated measures and Tukey's test. For DC data, the Student t-test was applied. It was adopted a significance level of 5\% for all statistical tests.

Table 2: Means (M) and standard deviations (SD) of VH for top and bottom surfaces of the specimens for the studied resins

\begin{tabular}{|c|c|c|c|c|c|c|c|c|c|c|c|}
\hline \multirow[t]{2}{*}{ Surface } & \multirow[t]{2}{*}{ Resin } & \multicolumn{10}{|c|}{ Storage in saliva (days) } \\
\hline & & & 0 & 1 & 2 & 3 & 7 & 14 & 21 & 30 & 180 \\
\hline \multirow[t]{6}{*}{ Top (T) } & $\mathrm{S}-\mathrm{XT}^{+}$ & $M$ & 34.6 & 33.2 & 34.4 & 32.7 & 34.0 & 34.5 & 34.7 & 34.5 & 34.6 \\
\hline & & SD & 1.1 & 1.1 & 1.3 & 1.2 & 1.0 & 1.0 & 1.1 & 1.0 & 1.5 \\
\hline & & & c & $a b$ & c & a & bc & c & c & c & c \\
\hline & $Z-250^{+}$ & $M$ & 41.8 & 41.7 & 40.7 & 40.7 & 41.0 & 40.9 & 41.7 & 40.9 & 41.1 \\
\hline & & SD & 0.8 & 1.0 & 1.1 & 0.9 & 0.8 & 0.9 & 0.7 & 0.9 & 1.2 \\
\hline & & & a & a & a & a & a & a & a & a & a \\
\hline \multirow[t]{6}{*}{ Bottom (B) } & $\mathrm{S}-\mathrm{XT}^{+}$ & $M$ & 33.7 & 31.5 & 33.4 & 31.1 & 32.0 & 32.8 & 33.5 & 33.3 & 33.3 \\
\hline & & SD & 1.2 & 1.2 & 1.5 & 1.4 & 1.4 & 1.3 & 1.2 & 1.2 & 2.0 \\
\hline & & & $c$ & a & c & a & $a b$ & $\mathrm{bc}$ & c & $\mathrm{c}$ & c \\
\hline & Z- $250^{+}$ & $M$ & 41.1 & 39.8 & 39.3 & 38.1 & 39.2 & 38.7 & 40.1 & 39.7 & 38.9 \\
\hline & & SD & 1.1 & 1.1 & 1.2 & 0.9 & 1.0 & 1.2 & 0.8 & 1.0 & 0.9 \\
\hline & & & c & $\mathrm{bc}$ & $a b$ & a & $a b$ & $a b$ & $\mathrm{bc}$ & $b$ & $a b$ \\
\hline
\end{tabular}

${ }^{+}$Means significantly different between resins at $p<0.001$

Means followed by same letters in the same row are not significantly different at $p<0.05$ 


\section{RESULTS}

\section{Hardness Measurements}

The mean values, standard deviations and statistical comparison for $\mathrm{VH}$ of the experimental groups formed by combining resins $v s$ storage-periods are summarized in Table 2 . The results show that there were significant differences between the averages of S-XT and Z-250, for both top and bottom surfaces, whatever the storage-period in artificial saliva $(p<0.001)$. The mean $\mathrm{VH}$ values of $\mathrm{Z}-250$ are all greater than the mean VH values of S-XT. After 180 days of storage in artificial saliva S-XT resin showed mean $\mathrm{VH}$ values statistically similar to the baseline measures (0 days), for both top and bottom. While the resin Z-250 showed similarity between the baseline and final measurement only for the top surface, so that the bottom surface demonstrated statistically significant decrease in mean $\mathrm{VH}$ values in the end of 180 days.

Table 3 shows the VH ratio between bottom and top surfaces. All averages are close to 1, indicating little change in hardness toward the bottom surface. There was no statistical difference between composites regarding the bottom/top ratio $(\mathrm{p}>0.05)$.

\section{Degree of Conversion (\%)}

Regarding DC (\%), Student t-test detected no difference between the mean percentages $(p=0.252)$. The DC $(\%)$ of S-XT $(55.1 \pm 2.6)$ was statistically similar to that of Z-250 $(57.1 \pm 3.7)$.

\section{DISCUSSION}

Since, the creation of the first composite, ${ }^{6}$ many efforts have been made to improve the clinical performance of this esthetic restorative material. Researches directed to this aim have focused on the development of the polymeric matrix ${ }^{24-27}$ and the characteristics of inorganic filler particles, such as type, management and content. ${ }^{28-30}$ Although both organic and inorganic phases of the resin are capable of influencing the material behavior, the amount and characteristics of the filler particles are the most important factors for improving the mechanical properties of the composites. ${ }^{10,30-32}$ The study developed by Kim et $\mathrm{al}^{31}$ showed that flexural strength, flexural modulus, hardness and fracture resistance of composite resins were significantly influenced by the morphology and content of filler particles.

Currently, several types of composite resins are commercially available for replacement of natural tooth tissues. The nanofilled composites are the latest in terms of restorative materials suitable for both anterior and posterior teeth. According to the manufacturer (3M ESPE) of a typical nanofilled composite, the product has physical properties similar to those of microhybrid and hybrid composites, what was confirmed by studies published in the literature. ${ }^{29,33}$ In this study, the nanofilled (S-XT) and microhybrid (Z-250) resins were compared regarding their degree of conversion and degradation pattern, so that all findings about these properties were discussed taking into account only the influence of the filler particles, since according to the manufacturer (3M ESPE) both resins have the same composition with respect to the polymer matrix.

To achieve improvements in physical properties and also in the clinical performance of composite resins, proper curing or high degree of conversion are essential factors. An inadequate polymerization may cause decreased physical properties, solubility in the oral environment and more susceptibility to microleakage, which can cause recurrent caries and pulp irritation. ${ }^{10,17,25,32,34-36}$ The degree of conversion is defined as the percentage of reacted $\mathrm{C}=\mathrm{C}$ aliphatic bonds of dimethacrylate monomer present in the polymeric matrix of the resin, and the extent of this response is directly related to the clinical success of restorations. ${ }^{37}$ Ideally, dental composites should have all of its monomer converted into polymer during the polymerization reaction. ${ }^{36,38}$ However, the dimethacrylate monomers used in restorative materials exhibit significant residual unsaturation at the end of the reaction, and the final conversion under clinical conditions is typically between 43 and $75 \%{ }^{3}{ }^{3,14,15,38,39}$ These values agree with the degree of conversion observed in this study that showed an average of $55.1 \%$ (nanofilled resin) and $57.1 \%$ (microhybrid resin) and this result is in accordance with those obtained in other

\begin{tabular}{|c|c|c|c|c|c|c|c|c|c|c|c|}
\hline \multirow[t]{2}{*}{ Surface } & \multirow[t]{2}{*}{ Resin } & \multicolumn{10}{|c|}{ Storage in saliva (days) } \\
\hline & & & 0 & 1 & 2 & 3 & 7 & 14 & 21 & 30 & 180 \\
\hline \multirow[t]{6}{*}{$\mathrm{B} / \mathrm{T}^{++}$} & $\mathrm{S}-\mathrm{XT}$ & M & 0.97 & 0.95 & 0.96 & 0.94 & 0.95 & 0.94 & 0.97 & 0.97 & 0.96 \\
\hline & & DP & 0.03 & 0.02 & 0.02 & 0.02 & 0.02 & 0.02 & 0.02 & 0.02 & 0.03 \\
\hline & & & $b$ & a & $a b$ & a & a & a & $a b$ & $a b$ & $a b$ \\
\hline & Z-250 & M & 0.98 & 0.95 & 0.96 & 0.94 & 0.96 & 0.95 & 0.96 & 0.97 & 0.95 \\
\hline & & DP & 0.03 & 0.02 & 0.01 & 0.02 & 0.02 & 0.02 & 0.01 & 0.02 & 0.03 \\
\hline & & & $b$ & $a$ & $a b$ & $a$ & $a$ & $a$ & $a b$ & $a b$ & $a b$ \\
\hline
\end{tabular}

++ No significant difference between resins regarding $B / T$ at $p>0.05$

Means followed by same letters in the same row are not significantly different regarding $B / T$ ratio at $p<0.05$ 
studies that used the FT-IR spectroscopy to measure the degree of conversion of resin composites. ${ }^{32,39,40}$

Some of the factors that determine degree of conversion of composite resins are: chemical composition of the material, curing time, power density and distance of the photocuring unit tip. ${ }^{3,14,32,33}$ In this study, variables related to polymerization were standardized, so that possible differences in materials could be attributed solely to differences in composition between them. Thus, it is likely that the similar organic matrix of the tested composite resins have determined equivalent degrees of conversion to both of them, while the difference in hardness between them must have occurred due to the characteristics of the filler particles. Since previous studies have found a correlation between the degree of conversion and mechanical properties, ${ }^{8,35,37}$ this finding was unexpected, considering that the similar degrees of conversion found for the tested resins did not accompany the differences in hardness between them. These findings agree with those of Silva et al. ${ }^{10}$

The depth of cure of the specimens was indirectly evaluated by the proportion between the initial $\mathrm{VH}$ values of the bottom and the top. ${ }^{41}$ In this study, the bottom/top relationship was similar and close to 1 for both materials. This result indicates a homogeneous polymerization for both the microhybrid and the nanofilled resin through the $2 \mathrm{~mm}$ thick specimens. Bottom/top average ratio of 0.92 was considered adequate in the study of Keogh et al. ${ }^{42}$ In this work, bottom/top ratio was above 0.92 for both resins. Similar results were obtained in a previous study, which showed that the mean $\mathrm{VH}$ of a microhybrid composite on the top and bottom surfaces were very similar when the polymerization was performed with a LED source. ${ }^{41}$ According to Fujita et $\mathrm{al},{ }^{43}$ if the amount of light reaching the bottom surface of the resin is high, the depth of cure will also be high. Thus, we can assume that the resins tested in this study allow adequate light transmission to the bottom of a $2 \mathrm{~mm}$ thick increment.

In addition to demonstrate physical, chemical, biological and esthetic worsened properties, underpolymerized composite resin restorations are also more susceptible to hydrolytic degradation. The hydrolytic degradation phenomenon occurs primarily by the accumulation of water at the charge/matrix interface, being the osmotic pressure generated in silane bonds the main cause of hydrolysis of a resin. ${ }^{22}$ This occurs because the water in contact with the surfaces of silica particles can break these silane bonds ${ }^{4,28}$ and the hydrolysis can lead to the displacement of particles. ${ }^{6}$ The water can actively participate in the cleavage of polymer bonds, but also serve as a medium for the action of enzymes. ${ }^{44}$ According to Feilzer et al, ${ }^{45}$ the absorption of water would have a beneficial effect by causing relaxation of the stress generated by polymerization shrinkage, however another study says that this absorption is insufficient to cause linear expansion which compensates the polymerization shrinkage, bringing more damages than benefits, since it can compromise the mechanical properties of the resin-based material. ${ }^{46}$

The resistance to degradation in the oral environment is essential for the longevity of the composite resin restorations. ${ }^{4}$ Saliva is a fluid with complex composition, which involves organic and inorganic compounds and microorganisms, so that the dental restorative composites must be able to resist changes that this environment can produce. ${ }^{18}$ In this study, artificial saliva was selected as storage medium for evaluation of hydrolytic degradation of the resins at a temperature of $37^{\circ} \mathrm{C}$, in order to simulate the effect of moisture from the buccal cavity, the inorganic components of saliva and temperature on the hardness of the studied materials.

Several authors have studied the effects of fluids such as saliva and distilled water on the mechanical properties of resin-based materials. ${ }^{17,22,23,47}$ Soderholm et al ${ }^{22,47}$ detected leached particles from resin composites stored in artificial saliva as well as in distilled water. In addition, a study assessing the hardness of resin-based materials over a year, demonstrated that excess water acts as a plasticizer on these materials. ${ }^{23}$ In general, this plasticizing effect was not observed at resins evaluated in this study under immersion in artificial saliva for 6 months. This finding contradicts the assertion of some authors, ${ }^{4,48}$ who said that the large relative surface-area/volume coming from the silica particles of the nanofilled composites can increase their absorption of water, leading to degradation of the filler/matrix interface and reduction of some mechanical properties. However, it corroborates with the findings of Okada et al ${ }^{17}$ who evaluated the $\mathrm{VH}$ of resinbased materials immersed in human saliva for a period of 40 days.

Santos et $\mathrm{al}^{49}$ observed by SEM evaluation that specimens of S-XT resin immersed in artificial saliva for 60 days showed small and homogeneous organic matrix degradation, leading to exposure of filler particles. In the same study it was observed the deposition of calcium in degraded areas of the matrix on the surface of specimens, which was attributed to the frequent contact of specimens with artificial saliva. The balance between these phenomena of matrix degradation and deposition of calcium may have been responsible for the slight variation in hardness values throughout the experimental period adopted in the present study.

The hardness of a resin-based material is a property that directly influences their clinical longevity. By definition, it is the ability of a material to resist penetration by a hard tip, and it is directly proportional to its mechanical strength and wear resistance. ${ }^{21}$ For these reasons, we used VH measurements as a means of analyzing the resins behavior over time with regard to the degradation in artificial saliva. 
According to the results shown in Table 2, there were some statistically significant differences over the 180-day trial, particularly to the bottom surface of the resin Z-250. However, it is worth to note that these differences may not have important practical interpretation, since the averages differ by only about two Vickers units, proportionally small when compared to the average.

As there were no significant decreases in hardness values over time, and this mechanical property has direct relationship with the longevity of resin-based materials ${ }^{17,23,28}$ and inverse to the degradation of them, we can infer that the composite resins Z-250 and S-XT presented hydrolytic stability in a 6 months period and showed a similar pattern of behavior over time for both surfaces evaluated (top and bottom), respecting their initial different hardness. The difference in hardness between resins contradicts the manufacturer's statement that the nanofiller composites have physical properties equivalent to hybrid and microhybrid ones. However, further studies are needed in order to assess whether these differences are clinically important enough to interfere in other mechanical properties of restorative materials, as well as understanding the effects of the hydrolytic phenomena on them.

\section{CONCLUSION}

The materials tested showed no evidence of hydrolytic degradation in a significant way, in a 6-month storage-time in artificial saliva.

Degree of conversion of the nanofilled resin is similar to the conventional microhybrid.

The microhybrid resin showed better performance concerning the mechanical property hardness.

\section{REFERENCES}

1. Amirouche-Korichia A, Mouzalib M, Watts DC. Effects of monomer ratios and highly radiopaque fillers on degree of conversion and shrinkage-strain of dental resin composites. Dent Mater 2009;25:1411-1418.

2. Alpöz AR, Ertugrul F, Cogulu D, Ak AT, Tanoglu M, Kaya E. Effects of light curing method and exposure time on mechanical properties of resin based dental materials. Eur J Dent 2008;2:37-42.

3. Moraes LGP, Rocha RSF, Menegazzo LM, Araújo EB, Yukimitu $\mathrm{K}$, Moraes JCS. Infrared spectroscopy: a tool for determination of the degree of conversion in dental composites. J Appl Oral Sci 2008;16:145-149.

4. Silva EM, Almeida GS, Poskus LT, Guimarães JGA. Relationship between the degree of conversion, solubility and salivary sorption of a hybrid and a nanofilled resin composite: influence of the light-activation mode. J Appl Oral Sci 2008;16:161-166.

5. Asmussen E, Peutzfeldt A. Influence of UEDMA BisGMA and TEGDMA on selected mechanical properties of experimental resin composites. Dent Mater 1998;14:51-56.

6. Bowen RL. Properties of silica reinforced polymer of dental restorations. J Am Dent Assoc 1963;1:57-64.

7. Peutzfeldt A. Resin composites in dentistry: the monomer systems. Eur J Oral Sci 1997;105:97-116.
8. Chung KH, Greener HE. Correlation between degree of conversion, filler concentration and mechanical properties of posterior composite resins. J Oral Rehabil 1990;17:487-494.

9. Imazato S, Tarumi H, Kobayashi K, Hiraguri H, Oda K, Tsuchitani Y. Relationship between the degree of conversion and internal discoloration of light-activated composite. Dent Mater J 1995;14:23-30.

10. Silva EM, Poskus LT, Guimarães JGA. Influence of lightpolymerization modes on the degree of conversion and mechanical properties of resin composites: a comparative analysis between a hybrid and a nanofilled composite. Oper Dent 2008;33:287-293.

11. Sideridou I, Tserki V, Papanastasiou G. Study of water sorption, solubility and modulus of elasticity of light-cured dimethacrylate-based dental resins. Biomaterials 2003;24: 655-665.

12. Hansel C, Leyhausen G, Mai UE, Geurtsen W. Effects of various resin composite (co) monomers and extracts on two cariesassociated micro-organisms in vitro. J Dent Res 1998;77:60-67.

13. Carmichael AJ, Gibson JJ, Walls AW. Allergic contact dermatitis to bisphenol-A-glycidyldimethacrylate (Bis-GMA) dental resin associated with sensitivity to epoxy resin. Br Dent J 1997; 183:297-298.

14. Halvorson RH, Erickson RL, Davidson CL. The effect of filler and silane content on conversion of resin-based composite. Dent Mater 2003;19:327-333.

15. Ferracane JL, Greener EH. Fourier transform infrared analysis of degree of polymerization in unfilled resins - methods comparison. J Dent Res 1984;8:1093-1095.

16. Lima AF, de Andrade KM, da Cruz Alves LE, Soares GP, Marchi GM, Aguiar FH, Peris AR, Mitsui FH. Influence of light source and extended time of curing on microhardness and degree of conversion of different regions of a nanofilled composite resin. Eur J Dent 2012;6:153-157.

17. Okada K, Tosaki S, Hirota K, Hume WR. Surface hardness change of restorative filling materials stored in saliva. Dent Mater 2001;17:34-39.

18. Mayworm CD, Camargo, SS Jr. Bastian FL. Influence of artificial saliva on abrasive wear and microhardness of dental composites filled with nanoparticles. J Dent 2008;36:703-710.

19. Prakki A, Cilli R, Mondelli RFL, Kalachandra S, Pereira JC. Influence of $\mathrm{pH}$ environment on polymer based dental material properties. J Dent 2005;33:91-98.

20. Sadr A, Ghasemi A, Shimada Y, Tagami J. Effects of storage time and temperature on the properties of two self-etching systems. J Dent 2007;35:218-225.

21. Yap AUJ, Tan SHL, Wee SSC, Lee CW, Lim ELC, Zeng KY. Chemical degradation of composite restoratives. J Oral Rehabil 2001;28:1015-1021.

22. Söderholm KJ, Zigan M, Ragan M, Fischlschweiger W, Bergman M. Hydrolytic degradation of dental composites. J Dent Res 1984;63:1248-1254.

23. Kanchanavasita W, Anstice HM, Pearson GJ. Long-term surface micro- hardness of resin-modified glass ionomers. J Dent 1998;26:707-712.

24. Pfeifer CS, Ferracane JL, Sakaguchi RL, Braga RR. Photoinitiator content in restorative composites: influence on degree of conversion, reaction kinetics, volumetric shrinkage and polymerization stress. Am J Dent 2009;22:206-210.

25. Pfeifer CS, Silva LR, Kawano Y, Braga R. Bis-GMA copolymerizations: influence on conversion, flexural properties, fracture toughness and susceptibility to ethanol degradation of experimental composites. Dent Mater 2009;25:1136-1141. 
26. Schneider LF, Pfeifer CS, Consani S, Prahl SA, Ferracane JL. Influence of photoinitiator type on the rate of polymerization, degree of conversion, hardness and yellowing of dental resin composites. Dent Mater 2008;24:1169-1177.

27. Vasudeva G. Monomer systems for dental composites and their future: a review. J Calif Dent Assoc 2009;37:389-398.

28. Berger SB, Palialol ARM, Cavalli V, Giannini M. Characterization of water sorption, solubility and filler particles of light-cured composite resins. Braz Dent J 2009;20:314-318.

29. Beun S, Glorieux T, Devaux J, Vreven J, Leloup G. Characterization of nanofilled compared to universal and microfilled composites. Dent Mater 2007;23:51-59.

30. Turssi CP, Ferracane JL, Vogel K. Filler features and their effects on wear and degree of conversion of particulate dental resin composites. Biomaterials 2005;26:4932-4937.

31. Kim KH, Ong JL, Okuno O. The effect of filler loading and morphology on the mechanical properties of contemporary composites. J Prosthet Dent 2002;87:642-649.

32. Saade EG, Bandéca MC, Saade JL, Rossato DM, Rastelli ANS, Bagnato VS, Porto-Neto ST. Effect of preheating resin composite and light-curing units on monomer conversion. Laser Phys 2010;20:285-290.

33. Rodrigues Junior SA, Zanchi CH, Carvalho RV, Demarco FF. Flexural strength and modulus of elasticity of different types of resin-based composites. Braz Oral Res 2007;21:16-21.

34. Conti C, Giorgini E, Landi L, Putignano A, Tosi G. Spectroscopic and mechanical properties of dental resin composites cured with different light sources. J Mol Struct 2005;744-7:641-646.

35. Ferracane JL, Greener EH. The effect of resin formulation on the degree of conversion and mechanical properties of dental restorative resins. J Biomed Mater Res 1986;20:121-131.

36. Rastelli ANS, Jacomassi DP, Bagnato VS. Degree of conversion and temperature increase of a composite resin light cured with an argon laser and blue LED. Laser Phys 2008;18:1570-1575.

37. Ferracane JL. Correlation between hardness and degree of conversion during the setting reaction of unfilled dental restorative resins. Dent Mater 1985;1:11-14.

38. Silikas N, Eliades G, Watts DC. Light intensity effects on resin composite degree of conversion and shrinkage strain. Dent Mater 2000;16:292-296.

39. Costa SXS, Martins LM, Franscisconi PAS, Bagnato VS, Saad JRC, Rastelli ANS, Andrade MF. Influence of different light sources and photoactivation methods on degree of conversion and polymerization shrinkage of a nanocomposite resin. Laser Phys 2009;19:2210-2218.

40. Silva EM, Gonçalves L, Guimarães JGA, Poskus LT, Fellows CE. The diffusion kinetics of a nanofilled and a midifilled resin composite immersed in distilled water, artificial saliva, and lactic acid. Clin Oral Invest 2011;15(3):393-401.

41. Saade EG, Bandeca MC, Rastelli ANS, Bagnato VS, Porto-Neto ST. Influence of pre-heat treatment and different light-curing units on vickers hardness of a microhybrid composite resin. Laser Phys 2009;19:1276-1281.

42. Keogh P, Ray NJ, Lynch CD, Burke FM, Hannigan A. Surface microhardness of a resin composite exposed to a 'firstgeneration' LED curing lamp, in vitro. Eur J Prosthodont Restor Dent 2004;12:177-180.

43. Fujita K, Nishiyama N, Nemoto K, Okada T, Ikemi T. Effect of base monomer's refractive index on curing depth and polymerization conversion of photo-cured resin composites. Dent Mater J 2005;24:403-408.
44. Guimarães FBR, Gomes HR, Fonseca RS, Barros LM, Marinho VA, Freitas ABDA. Influence of polymerization time of different composites on water sorption. Rev Odonto Ciênc 2008;23:67-71.

45. FeilzerAJ, de GeeAJ, Davidson CL. Relaxation of polymerization contraction shear stress by hygroscopic expansion. J Dent Res 1990;69:36-39.

46. Hirasawa T, Hirano S, Hirabayashi S, Harashima I, Aizawa M. Initial dimension change of composites in dry and wet conditions. J Dent Res 1983;62:28-31.

47. Söderholm KJ, Mukherjee R, Longmate J. Filler leachability of composites stored in distilled water or artificial saliva. J Dent Res 1996;75:1692-1699.

48. Kalachandra S, Wilson TW. Water sorption and mechanical properties of light-cured proprietary composite tooth restorative materials. Biomaterials 1992;13:105-109.

49. Santos PA, Garcia PPNS, Oliveira ALBM, Chinelatti MA, Palma-Dibb RG. Chemical and morphological features of dental composite resin: influence of light curing units and immersion media. Microsc Res Techniq 2010;73:176-181.

\section{ABOUT THE AUTHORS}

\section{Fernanda Ferreira Jassé (Corresponding Author)}

PhD Student, Department of Restorative Dentistry, São Paulo State University School of Dentistry, Araraquara, Brazil, Phone: +55 16 33016388 e-mail: fernandajasse@hotmail.com

\section{Carlos Henrique Braga Borges}

Master Student, Department of Restorative Dentistry, São Paulo State University School of Dentistry, Araraquara, SP, Brazil

\section{Mateus Rodrigues Tonetto}

Professor of the Post Graduation in Integrated Dental Sciences University of Cuiaba, MT, Brazil

\section{Alessandra Nara de Souza Rastelli}

Professor, Department of Restorative Dentistry, São Paulo State University School of Dentistry, Araraquara, SP, Brazil

\section{Vanderlei Salvador Bagnato}

Chief, Optics Group from Institute of Physics of São Carlos, University of São Paulo, São Carlos, SP, Brazil

\section{Edson Alves de Campos}

Professor, Department of Restorative Dentistry, São Paulo State University School of Dentistry, Araraquara, SP, Brazil

\section{Reidson Stanley Soares dos Santos}

Master Student, Post-Graduation in Dentistry, CEUMA University São Luis, MA, Brazil

\section{Matheus Coelho Bandeca}

Professor of the Post-Graduation in Dentistry, CEUMA University São Luis, MA, Brazil

\section{José Roberto Cury Saad}

Professor, Department of Restorative Dentistry, São Paulo State University School of Dentistry, Araraquara, SP, Brazil 